\title{
Evidence-Based Treatment for Depressive Disorder
}

\author{
Chi-Un Pae ${ }^{1,2 \bowtie}$ \\ ${ }^{1}$ Department of Psychiatry, The Catholic University of Korea College of Medicine, Seoul, Republic of Korea \\ ${ }^{2}$ Department of Psychiatry and Behavioral Sciences, Duke University Medical Center, Durham, NC, USA
}

Dear Sir: I have read with great interest the paper by Wang et al. ${ }^{1}$ comparing the Korean Medication Algorithm for Depressive Disorder (KMAD) with other treatment guidelines (TGs) from different academic societies across the world.

Herein I would like to complement and update the authors' perspectives with presentation of more wide range of TGs, the position of TGs and their role for clinical practice. Evidencebased and informed clinical decision-making process will clearly improve treatment outcomes. In this context, TG is systematically developed and intended to give a huge help for clinicians' and patients' prudent decisions at specific clinical circumstances. Currently the role of TG has been dramatically increased and also considered highly crucial in establishment and reformation of optimal health policy by government and insurance company as well as being an efficient and proven scientific base leading to the continuum of best care. ${ }^{2-4}$ In fact, improved treatment outcomes with guideline-based care have been consistently reported compared to routine treatment. ${ }^{5}$ For instance, an algorithm based care for depression based on the Texas Medication Algorithm Project (TMAP) in the U.S. ${ }^{6}$ was compared to treatment as usual (TAU) in 12 clinics over 12 months in U.S. The TMAP-based intervention was associated with significantly better clinical outcomes than TAU.

As Wang et al. ${ }^{1}$ stated, Korean psychiatrists need to fix and advance the KMAD in comparison with those from other countries. However, in this context, the most update TG version, different regulatory authority's stance to approval of medication and public health insurance system as well as different social and cultural backgrounds in individual countries or regions, have to be implemented.

Received: March 1, 2014 Revised: April 30, 2014

Accepted: April 30, 2014 Available online: March 18, 2015

$\triangle$ Correspondence: Chi-Un Pae, MD, PhD

Department of Psychiatry, Bucheon St. Mary's Hospital, The Catholic University of Korea College of Medicine, 327 Sosa-ro, Wonmi-gu, Bucheon 420-717, Republic of Korea

Tel: +82-32-340-2140, Fax: +82-32-340-2255, E-mail: pae@catholic.ac.kr

(a) This is an Open Access article distributed under the terms of the Creative Commons Attribution Non-Commercial License (http://creativecommons.org/licenses/bync/3.0) which permits unrestricted non-commercial use, distribution, and reproduction in any medium, provided the original work is properly cited.
Unfortunately, Wang et al included 5 TGs only from Western side, such as APA 2010, ${ }^{7}$ CANMAT 2009, ${ }^{8}$ NICE 2010, ${ }^{9}$ TMAP 2008, ${ }^{6}$ and WFSBP $2007 .{ }^{10}$ Excluding TMAP from expert consensus (EC), others are all evidence-based, the later ones are more convincing than the former one. EC is also partly from evidence but it has not been considered true evidence since the reliable criteria for expert selection is not based on scientific ways and the opinions are totally from personal experiences. The most updated TG has been performed by the WFSBP, which has been already revised in $2013,{ }^{11}$ thus the WFSBP $2007^{10}$ is not the right citation. In WFSBP 2013 revision, some updates are available as followings: regarding antidepressant $(\mathrm{AD})$ monotherapy vs. combination therapy, the results from COMED study ${ }^{12}$ had been cited without clear recommendations; the specific response criteria for antidepressant treatment has been given; early improvement concept has been also introduced without specific recommendation; newer $\mathrm{AD}$ such as agomelatine data has been also given and incorporated and the WFSBP 2013 now recommends the use of quetiapine and aripiprazole for patients those who failed to show response to $\mathrm{AD}$ monothrapy regardless of presence of the psychotic symptoms. In addition, all guidelines cited in Wang et al's paper1 do not recommend the initial trial of $\mathrm{AD}$ for mild depression but recommend a brief psychotherapy or even just simple counselling against their assertion; $\mathrm{AD}$ is usually recommended for moderate to severe depression. Likewise, other missed or wrong points exists somewhere in Wang et al.s paper. It is also unclear why they did not cite the TGs from the British (BAP 2008) ${ }^{13}$ and German (DGPPN 2010) ${ }^{14}$ psychopharmacology society. They are highly reliable and rigorous ones showing different stances toward some recommendations compared to 5 guidelines they cited. For instance, the BAP 2008 and DGPPN 2010 do not recommend the augmentation of antipsychotics for depression. The BAP 2008 specifies the recommendation of augmentation agent with category of $\mathrm{A} / \mathrm{B} / \mathrm{C} / \mathrm{D}$ with level of evidence. In addition, regarding light therapy for seasonal affective disorder, the WFSBP 2013 does not recommend light therapy as a routine 
option.

We also have to see TGs around Asian regions, although Wang et al. missed them. For instance, in China TG, ${ }^{15}$ if depression is still resistant to treatment after dose adjustment and re-evaluation of proper diagnosis, the second-line strategies may include switching to tricyclic ADs (TCAs) and combining $\mathrm{AD}$ with another $\mathrm{AD}$ or a mood stabilizer, but not include antipsychotics as augmentation agents (AAs). Despite TCAs are shown as a second-line treatment in the TG, TCAs are often employed as first-line agents due to new ADs availability and cost issues in China. As for Japanese TG, ${ }^{16}$ antipsychotics are not also included as routine AA, even if patient had psychotic depression, antipsychotics are only allowed upon agitation plus suicidal risk, the first agent is amoxapine for psychotic depression without such symptoms. Despite other strategic ways for moderate to severe depression are relatively similar to other TGs, the Japanese TGs have 3 different treatment algorithms for each specific purpose. ${ }^{17}$

Another point is that relatively less emphasis placed on antipsychotics for augmentation on the BAP 2008, DGPPN 2010 and WFSBP 2007 TGs, may reflect that the availability of a body of evidence at the time of the TG development is highly important. In fact, quetiapine XR was approved by the European Medicines Agency (EMA) in April 2010; however, aripiprazole has not yet been approved for treating depression in Europe; indeed the manufacturer Otsuka withdrew its filing to the EMA due to long-term data issue on 2011. Likewise aripiprazole augmentation for depression has been just approved on 2013 in Japan, even the drug was developed in Japan. Given aforementioned, the principal differences of TGs among countries or regions may stem from the availability of high quality data, viewpoint of regulatory authority, availability of certain drug with approved indication, national health insurance policy including reimbursement system, promotional activity of pharmaceutical company and medical cost at the time of TG documentation.

In conclusion, the potential benefits of TGs are only as good as the quality of themselves. Clear and proper methodologies, rigorous strategies and exchangeable criticism on TG data under consideration are more important in the TG development process than rapid establishment of recommendations. ${ }^{18}$ The effectiveness of TG implementation must also be assessed, regularly updated and given a wide range of public feedback to be validated. Additionally, a concise version of the guideline should be developed for easy, convenient and wide application for clinicians in busy routine practice.

\section{Acknowledgments}

This study was partially funded by the Ministry of Health and Welfare, Korea (HI12C0003).

\section{REFERENCES}

1. Wang HR, Bahk WM, Park YM, Lee HB, Song HR, Jeong JH, et al. Korean medication algorithm for depressive disorder: comparisons with other treatment guidelines. Psychiatry Investig 2014;11:1-11.

2. Woolf SH, Grol R, Hutchinson A, Eccles M, Grimshaw J. Clinical guidelines: potential benefits, limitations, and harms of clinical guidelines. BMJ 1999;318:527-530.

3. Schulberg HC, Katon W, Simon GE, Rush AJ. Treating major depression in primary care practice: an update of the Agency for Health Care Policy and Research Practice Guidelines. Arch Gen Psychiatry 1998; 55:1121-1127.

4. Patkar AA, Pae CU. Atypical antipsychotic augmentation strategies in the context of guideline-based care for the treatment of major depressive disorder. CNS Drugs 2013;27(Suppl 1):S29-S37.

5. Trivedi MH, Rush AJ, Crismon ML, Kashner TM, Toprac MG, Carmody TJ, et al. Clinical results for patients with major depressive disorder in the Texas Medication Algorithm Project. Arch Gen Psychiatry 2004;61:669-680.

6. Suehs BT AT, Bendele SD, Crismon ML, Trivedi MH, Kurian B. Texas Medication Algorithm Project Procedural Manual: Major Depressive Disorder Algorithms. Austin, TX: Texas Department of State Health Services; 2008. http://www.dshs.state.tx.us/mhprograms/disclaimer. shtm. Accessed August 20, 2012.

7. American Psychiatric Association. Practice Guideline for the Treatment of Patients With Major Depressive Disorder, Third Edition. Washington, D.C.: American Psychiatric Publishing; 2010.

8. Lam RW, Kennedy SH, Grigoriadis S, McIntyre RS, Milev R, Ramasubbu R, et al. Canadian Network for Mood and Anxiety Treatments (CANMAT) clinical guidelines for the management of major depressive disorder in adults. III. Pharmacotherapy. J Affect Disord 2009;117 (Suppl 1):S26-S43.

9. Excellence NIfHC. Depression: the treatment and management of depression in adults; 2009

10. Bauer M, Bschor T, Pfennig A, Whybrow PC, Angst J, Versiani M, et al. World Federation of Societies of Biological Psychiatry (WFSBP) Guidelines for Biological Treatment of Unipolar Depressive Disorders in Primary Care. World J Biol Psychiatry 2007;8:67-104.

11. Bauer M, Pfennig A, Severus E, Whybrow PC, Angst J, Moller HJ, et al. World Federation of Societies of Biological Psychiatry (WFSBP) guidelines for biological treatment of unipolar depressive disorders, part 1 : update 2013 on the acute and continuation treatment of unipolar depressive disorders. World J Biol Psychiatry 2013;14:334-385.

12. Rush AJ, Trivedi MH, Stewart JW, Nierenberg AA, Fava M, Kurian BT, et al. Combining medications to enhance depression outcomes (CO$\mathrm{MED}$ ): acute and long-term outcomes of a single-blind randomized study. Am J Psychiatry 2011;168:689-701.

13. Anderson IM, Ferrier IN, Baldwin RC, Cowen PJ, Howard L, Lewis G, et al. Evidence-based guidelines for treating depressive disorders with antidepressants: a revision of the 2000 British Association for Psychopharmacology guidelines. J Psychopharmacol 2008;22:343-396.

14. Harter M, Klesse C, Bermejo I, Schneider F, Berger M. Unipolar depression: diagnostic and therapeutic recommendations from the current S3/National Clinical Practice Guideline. Dtsch Arztebl Int 2010; 107:700-708.

15. Zhang M. Major depressive disorder treatment guidelines in China. J Clin Psychiatry 2010;71(Suppl E1):e06.

16. Motohashi N, Shioe K, Nakamura J, Ohshima A, Yamada K, Ozawa H, et al. Revised psychopharmacological algorithms for the treatment of mood disorders in Japan. Int J Psychiatry Clin Pract 2008;12:11-18.

17. Higuchi T. Major depressive disorder treatment guidelines in Japan. J Clin Psychiatry 2010;71(Suppl E1):e05.

18. Owens DK, Lohr KN, Atkins D, Treadwell JR, Reston JT, Bass EB, et al. AHRQ series paper 5: grading the strength of a body of evidence when comparing medical interventions--agency for healthcare research and quality and the effective health-care program. J Clin Epidemiol 2010; 63:513-523. 